\title{
Research on natural gas pipeline leakage and ventilation scheme in tunnel
}

\author{
Hongfang $\mathrm{Lu}^{1,2}$, Kun Huang ${ }^{1}$, Lingdi Fu${ }^{1}$, Zhihao Zhang ${ }^{1}$, Shijuan Wu ${ }^{3}$, You Lyu ${ }^{4}$ \\ ${ }^{1}$ School of Petroleum Engineering, Southwest Petroleum University, Chengdu, Sichuan, China \\ ${ }^{2}$ Trenchless Technology Center, Louisiana Tech University, Ruston, Louisiana, USA \\ ${ }^{3}$ Guangxi Oil Production Plant, Southwest Oil and Gas Company, Sinopec, Deyang, Sichuan, China \\ ${ }^{4}$ Nanning Oil \& Gas Transmission Sub-Company, PetroChina Southwest Pipeline Company, Nanning, Guangxi, China
}

\begin{abstract}
Due to poor ventilation conditions in the tunnel, if gas pipeline leaks, the consequence of the accident will be more serious. Therefore, before the emergency repair, gas in the tunnel needs to be excharged so as not to explode during the repair process. Therefore, it is necessary to study the ventilation of gas in the tunnel. Based on the computational fluid dynamics (CFD) theory and taking the Yanyingshan tunnel section of China-Myanmar pipeline as an example, this paper uses Fluent software to establish the leakage model of the gas pipeline and fan model in the tunnel and analyzes the influence of different fan locations and number of fans on gas concentration. It can be concluded that: (1) the use of press-in method makes it more efficient to discharge gas out of the tunnel. (2) In order to make ventilation efficient, the fan should be arranged in a higher position and needs to be at a distance from the top of the tunnel. (3) Parallel use of two fans has better ventilation effect than single fan.
\end{abstract}

Keywords: tunnel; gas pipeline; leakage; computational fluid dynamics; ventilation scheme

\section{Introduction}

Based on the report "Gas Pipeline Incidents" written by EGIG (European Gas pipeline Incident data Group), from the statistical data from 1970 to 2013 , the accident caused by construction defects or material failures accounts for $16 \%$ of all accidents. ${ }^{1}$ In 2006, a gas pipeline in Respublika Severnaya Osetiya-Alaniya exploded, the gas pipeline passed through a tunnel and tunnel collapsed by this accident. After that, the pipeline exploded again, and the pipe was forced to stop. ${ }^{2}$ Therefore, after the gas pipeline leaks in the tunnel, emergency repair needs to be done, and gas gathered in the tunnel need to be discharged to avoid secondary accidents. Thus, it is necessary to study the leakage law of gas pipeline and ventilation scheme of the tunnel.

In 1997, Axel Bring et al. used assembly language to develop a simulation program that calculates the pressure changes and gas velocity changes along the gas pipeline in the tunnel. The model has some applicability, but the function is relatively simple and cannot be compared to many kinds of schemes. ${ }^{3}$ In 2001 , Wei Jinfeng et al. studied the application of Navier-Stokes equation in tunnel ventilation engineering and established a simple two-dimensional verification model to simulate the ventilation effect of wind tunnel with different length and height, but this research only studied the single-fan case, and did not study the situation of multi fans. ${ }^{4}$ In 2008 , Peng Fan analyzed the ventilation of long highway tunnels and discussed the control requirements of fans in different situations. ${ }^{5}$ In 2008 , Mónica GaldoVega et al. used a three-dimensional numerical simulation of the longitudinal ventilation system (LVS) to analyze the behavior of a fire in a highway tunnel. ${ }^{6}$ In 2009, Li Feng conducted a study on the ventilation management of high-concentration gas tunnels, discussed the management points of high-concentration gas tunnels and elaborated the 
construction experience. However, no computer simulation was conducted and only theoretical analysis was made. ${ }^{7}$ In 2013, Hu Chunliang studied the vertical tunnel ventilation scheme and proposed the optimization scheme. The experimental model was established by using the principle of water jet, and the computer simulation results were verified. ${ }^{8}$ In 2014, Huang Hao et al. Studied the application of high pressure and large flow fan in the tunnel and established a two-dimensional verification model to compare the effect of ventilation volume on ventilation. ${ }^{9}$

Based on survey on tunnel ventilation, the focus of the research is mainly on the tunnels in highway and railway, and the research on the tunnel of oil and gas pipeline is less. However, tunnel of oil and gas pipeline is very different from other tunnels. Its space is smaller, and there is no special air duct. In addition, there is a higher risk of oil and gas pipeline leakage and improper handling can cause serious explosions. Therefore, this paper uses numerical simulation method to study the ventilation scheme of oil and gas pipe tunnel.

\section{Basic theory}

(1) Leakage jet velocity

In the process of pipe leakage, the frictional influence of air flow at the leakage hole can be neglected, and assuming that there is no heat exchange with the outside, it can be considered that gas flows in the vicinity of the leakage hole as an isentropic process. Therefore, leakage jet velocity is:

$$
v_{2}=c \sqrt{\frac{2 k}{k-1} R T_{1}\left[1-\left(\frac{p_{2}}{p_{1}}\right)^{\frac{k-1}{k}}\right]}
$$

where $c$ is leakage jet velocity coefficient, it relates to the form of leaks, 0.65 for crack and 0.98 for circular hole; $k$ is specific heat ratio; $v_{2}$ is leakage jet speed, $\mathrm{m} / \mathrm{s} ; R$ is gas constant, $\mathrm{J} /(\mathrm{kg} \cdot \mathrm{K}) ; T_{1}$ is internal temperature of natural gas pipeline, $\mathrm{K} ; p_{2}$ is atmospheric pressure, $\mathrm{Pa} ; p_{1}$ is pipeline inner pressure, $\mathrm{Pa}$.

(2) Leakage rate

For non-critical flow:

$$
Q=c_{0} A P_{2} \sqrt{\frac{2 M k}{Z R T_{2}(k-1)}\left[\left(\frac{P_{\mathrm{a}}}{P_{2}}\right)^{\frac{2}{k}}-\left(\frac{P_{\mathrm{a}}}{P_{2}}\right)^{\frac{k+1}{k}}\right]}
$$

where $Q$ is gas leakage rate, $\mathrm{kg} / \mathrm{s} ; \mathrm{M}$ is molecular weight of gas, $\mathrm{kg} / \mathrm{mol} ; P_{\mathrm{a}}$ is atmospheric pressure outside pipe, $\mathrm{Pa} ; c_{0}$ is gas leakage coefficient; $Z$ is compressibility factor.

For critical flow and supercritical flow:

$$
Q=c_{0} A P_{2} \sqrt{\frac{M k}{Z R T_{2}(k-1)}\left(\frac{2}{k+1}\right)^{\frac{k+1}{k-1}}}
$$

(3) Duration of gas filled with tunnel:

$$
t=\frac{4 S \rho_{\mathrm{j}}\left(L_{1}-L^{\prime \prime}\right)}{35 Q(Q / 1000)^{-0.1} L_{1}^{-0.59}}+\frac{4000 S \rho_{j}\left(L-2 L_{1}\right)}{646837 c Q(c Q / 1000)^{-0.1} L_{1}^{-0.59}\left(L-2 L_{1}\right)^{-0.59}}+50
$$

where $S$ is section area of tunnel, $\mathrm{m}^{2} ; L_{1}$ is the smaller distance between leak and tunnel door, $\mathrm{m} ; \rho_{\mathrm{j}}$ is gas density under normal pressure, $\mathrm{kg} / \mathrm{m}^{3} ; Q$ is gas leak rate, $\mathrm{kg} / \mathrm{s} ; c$ is flow rate correction coefficient; $L$ is full length of tunnel, $\mathrm{m} ; L^{\prime \prime}$ is moving distance between gas and air at 50 seconds of leakage, $\mathrm{m}$.

(4) Turbulence model 
The standard $K-\varepsilon$ turbulence model is selected.

Turbulent kinetic energy equation ( $K$ equation):

$$
\frac{\partial}{\partial t}(\rho k)+\frac{\partial}{\partial x_{\mathrm{i}}}\left(\rho k u_{\mathrm{i}}\right)=\frac{\partial}{\partial x_{\mathrm{j}}}\left[\left(\mu+\frac{\mu_{\mathrm{t}}}{\sigma_{\mathrm{k}}}\right) \frac{\partial k}{\partial x_{\mathrm{j}}}\right]+G_{\mathrm{K}}+G_{\mathrm{b}}-\rho e-Y_{\mathrm{M}}+S_{\mathrm{k}}
$$

Diffusion equation ( $\varepsilon$ equation):

$$
\frac{\partial}{\partial t}(\rho e)+\frac{\partial}{\partial x_{\mathrm{i}}}\left(\rho e u_{\mathrm{i}}\right)=\frac{\partial}{\partial x_{\mathrm{j}}}\left[\left(\mu+\frac{\mu_{\mathrm{t}}}{\sigma_{\mathrm{e}}}\right) \frac{\partial e}{\partial x_{\mathrm{j}}}\right]+C_{1 e} \frac{e}{k}\left(G_{\mathrm{k}}+C_{3 \mathrm{e}} G_{\mathrm{b}}\right)-C_{2 \mathrm{e}} \rho \frac{e^{2}}{k}+S_{\mathrm{e}}
$$

where $G_{\mathrm{K}}$ is turbulent kinetic energy generated by buoyancy; $G_{\mathrm{b}}$ is turbulent kinetic energy generated by buoyancy; $Y_{\mathrm{M}}$ is undulation caused by excessive diffusion in compressible turbulence; $C_{1 \mathrm{e}}, C_{2 \mathrm{e}}, C_{3 \mathrm{e}}$ are constant and $C_{1 \mathrm{e}}=1.44, C_{2 \mathrm{e}}=1.92$, $C_{3 \mathrm{e}}=0.09 ; \sigma_{\mathrm{k}}$ and $\sigma_{\mathrm{e}}$ are Prandtl number of $K$ equation and $\varepsilon$ equation, respectively, and $\sigma_{\mathrm{k}}=1, \sigma_{\mathrm{e}}=1.3$.

(5) Component transport model

In order to study the distribution of natural gas in the tunnel, it is necessary to adopt component transport model:

$$
\frac{\partial}{\partial t}\left(\rho Y_{\mathrm{i}}\right)+\nabla \cdot\left(\rho \vec{v} Y_{\mathrm{i}}\right)=-\nabla \overrightarrow{j_{\mathrm{i}}}+R_{\mathrm{i}}+S_{\mathrm{i}}
$$

\section{Case study}

\subsection{Project overview}

The cross section size of Yanyingshan tunnel is $3.8 \mathrm{~m} \times 3.8 \mathrm{~m}$, the bottom is a rectangle, and the upper part is a semicircular arch. As shown in Fig. 1, the gas pipeline and the crude oil pipeline are laid in parallel with a distance of 1.2 $\mathrm{m}$. The refined oil pipeline is above the crude oil pipeline. The laying form is overhead laying, the specific parameters of gas pipeline are shown in Table 1, and the gas components are shown in Table 2 . In order to reduce the possibility of third party damage, as shown in Fig. 2, a brick-structured tunnel door with a vent of size $0.3 \mathrm{~m} \times 0.3 \mathrm{~m}$ will be constructed at both ends of the tunnel.

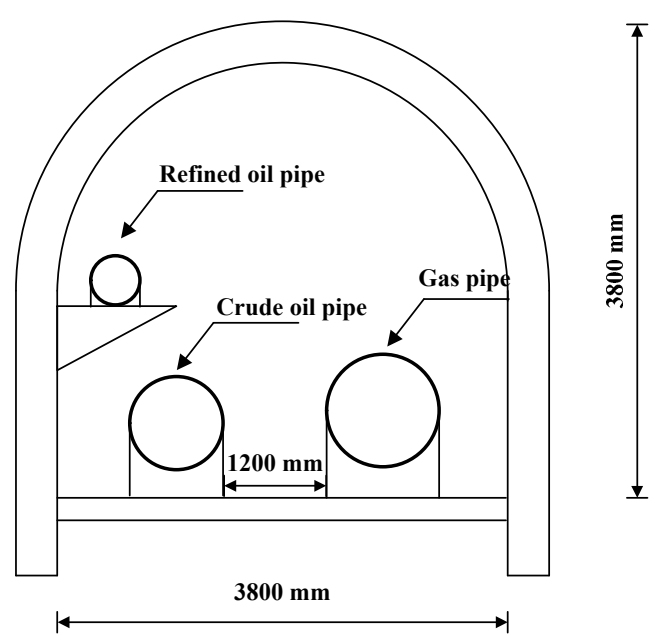

Fig.1 Layout diagram of pipes in Yanyingshan tunnel

Table 1. Parameters of pipes in Yanyingshan tunnel

\begin{tabular}{|c|c|c|c|c|c|}
\hline Diameter $(\mathrm{mm})$ & $\begin{array}{c}\text { Thickness (Straight pipe) } \\
(\mathrm{mm})\end{array}$ & $\begin{array}{c}\text { Thickness (Hot-bending } \\
\text { bend) }(\mathrm{mm})\end{array}$ & $\begin{array}{c}\text { Thickness (Cold-bending } \\
\text { bend) }(\mathrm{mm})\end{array}$ & Pressure (MPa) & Material \\
\hline 1016 & 28.6 & 31.8 & 28.6 & 10 & $\mathrm{X} 70$ \\
\hline
\end{tabular}


Table 2. Gas components

\begin{tabular}{|c|c|c|c|c|c|}
\hline Component & $\mathrm{CH}_{4}$ & $\mathrm{C}_{2} \mathrm{H}_{6}$ & $\mathrm{~N}_{2}$ & $\mathrm{CO}_{2}$ & $\mathrm{H}_{2} \mathrm{~S}$ \\
\hline Volume fraction (\%) & 93.984 & 2.972 & 1.934 & 0.683 & 0.427 \\
\hline
\end{tabular}

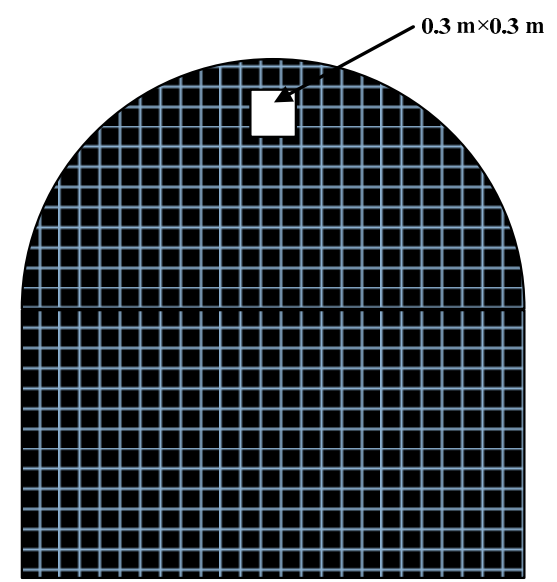

Fig. 2 Schematic diagram of the vent on the tunnel door

\subsection{Numerical simulation}

\section{(1) Grid generation}

Because of the complexity and uncertainty of the gas flow, the two-dimensional model cannot accurately describe the diffusion of gas in the tunnel, so a three-dimensional numerical simulation model is adopted. A high speed jet is produced at the leakage hole, the velocity and pressure gradient are relatively large. Therefore, in order to guarantee the accuracy of simulation, the grid at the pipeline leakage should be refined, taking into account the computational cost, we need to ensure that the total number of grids is in a certain range. Tetrahedral mesh is used near the leakage hole. The total length of the tunnel is about $2000 \mathrm{~m}$, therefore, in order to reduce the amount of calculation, the grid far away from the leakage hole can be rough, a part of grid result of tunnel model is shown in Fig. 3. The total number of grids is about 700 thousand, and the grid result of the whole tunnel is shown in Fig. 4.

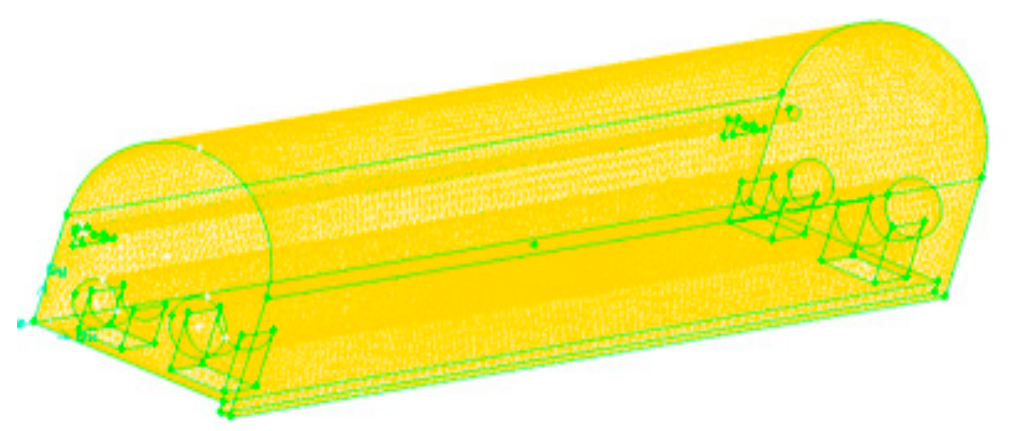

Fig.3 Grid of tunnel and pipe model (A part)

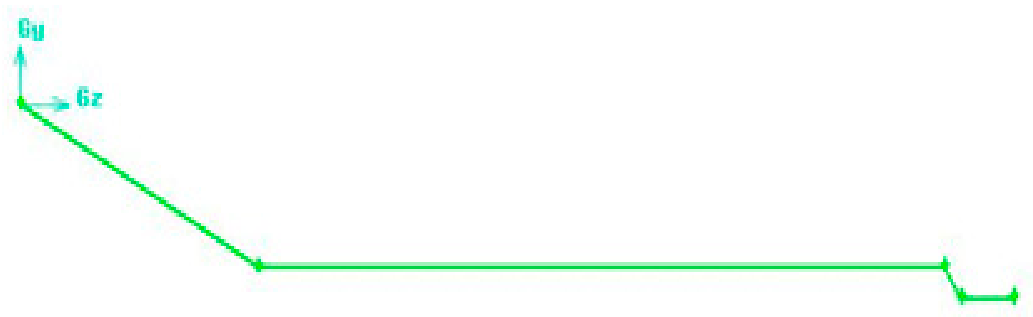

Fig.4 Grid of whole tunnel (1:1)

(2) Boundary condition 
Boundary conditions within the Yayingshan tunnel are divided into three sections: leakage hole of gas pipeline, tunnel wall and pipe wall, vents of export and import of tunnel.

Leakage hole of gas pipeline: Pressure import.

Tunnel wall and pipe wall: Wall boundary.

Vents of export and import of tunnel: Pressure outlet.

(3) Step of calculation

The ideal initial step is the minimum size of the grid divided by the maximum velocity of the fluid. During the calculation, it is guaranteed that the time step can be gradually increased with the convergence of the calculation. Select $0.0001 \mathrm{~s}$ based on the initial step.

\section{Results and discussions}

If the gas pipeline leaks in the tunnel, both ends of the valve chamber should be closed. As the leakage progresses, the pressure in the pipe decreases and the leakage rate decreases. When the pressure in the pipe is equal to the outside pressure, the leak stops. Therefore, it is necessary to obtain the relationship between the leakage rate and the internal pressure of the pipeline and calculate the total leakage, thus the duration of the leakage jet can be obtained.

\subsection{Relationship between leakage rate and pipeline pressure}

When the leakage area is $0.01 \mathrm{~m}^{2}$, different leakage rates can be obtained by changing the internal pressure of the pipeline, as shown in Fig. 5. The relationship between pipe internal pressure and leakage rate can be expressed as a one-quadratic equation:

$$
L_{r}=0.2009 p_{i}^{2}+16.76 p_{i}+0.0751\left(R^{2}=1\right)
$$

where $L_{r}$ is leakage rate, $\mathrm{kg} / \mathrm{s} ; p_{i}$ is internal pressure of pipeline, MPa.

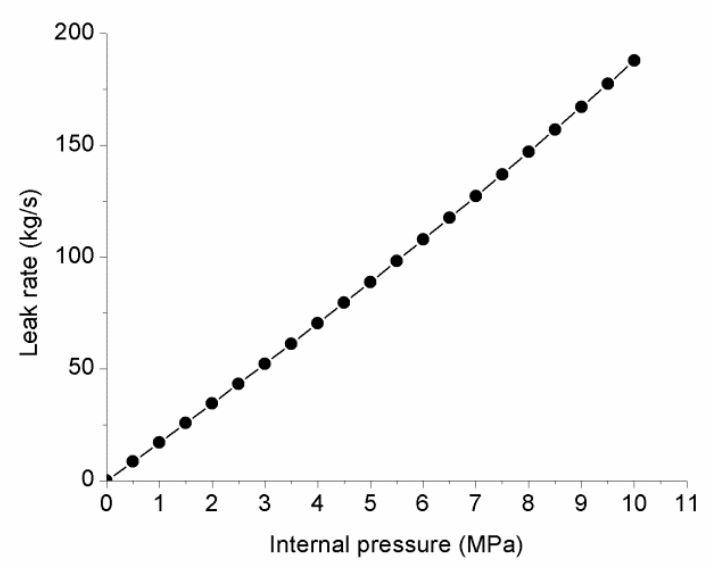

Fig.5 Relationship between internal pressure and leakage rate

\subsection{Relationship between leakage rate and leakage area}

When the internal pressure is $10 \mathrm{MPa}$, different leakage rates can be obtained by changing the leakage area of the pipeline, as shown in Fig. 6. The relationship between leakage area and leakage rate can be expressed as a one-quadratic equation:

$$
L_{r}=41657 p_{i}^{2}+17001 p_{i}+2.7214\left(R^{2}=0.9988\right)
$$

where $L_{r}$ is leakage rate, $\mathrm{kg} / \mathrm{s} ; p_{i}$ is internal pressure of pipeline, MPa. 


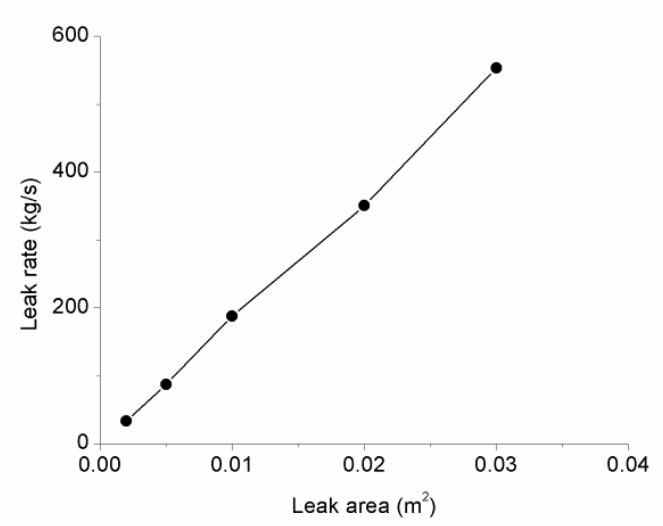

Fig.6 Relationship between leak area and leak rate

\subsection{Total leakage}

After the valve chambers at both ends of the leakage hole are closed, the amount of gas stored in the closed section can be calculated from the distance between the valve chambers, the internal pressure of the pipeline and the gas state in the pipeline:

$$
Q_{g}=A_{g} \times L \times \rho_{g}
$$

where $Q_{g}$ is gas stock in the pipeline when the valve chamber is closed, $\mathrm{kg} ; A_{g}$ is cross-sectional area of gas pipeline, $\mathrm{m}^{2}$; $L$ is distance between valve chambers at both ends, $\mathrm{m} ; \rho_{g}$ is gas density, $\mathrm{kg} / \mathrm{m}^{3}$.

The amounts of gas leakage corresponding to the different internal pressures are shown in Table 3.

Table 3. The amount of gas leakage corresponding to the different internal pressures

\begin{tabular}{|c|c|c|c|c|}
\hline $\begin{array}{l}\text { Internal pressure } \\
\qquad(\mathrm{MPa})\end{array}$ & Compression factor & $\begin{array}{l}\text { Total amount of gas storage } \\
\text { when the valve is closed }(\mathrm{kg})\end{array}$ & $\begin{array}{c}\text { Total amount of gas storage } \\
\text { when leak stopped }(\mathrm{kg})\end{array}$ & $\begin{array}{l}\text { Amount of } \\
\text { leakage }(\mathrm{kg})\end{array}$ \\
\hline 6 & 0.89 & 929690 & 14459 & 915232 \\
\hline 7 & 0.87 & 1108802 & 14459 & 1094343 \\
\hline 8 & 0.85 & 1295417 & 14459 & 1280959 \\
\hline 9 & 0.83 & 1489688 & 14459 & 1475230 \\
\hline 10 & 0.81 & 1691752 & 14459 & 1677294 \\
\hline
\end{tabular}

\subsection{Leakage jet duration}

The relationship between the total leakage and the leakage duration is:

$$
Q_{t}=A Q_{a} T
$$

where $Q_{t}$ is total leakage, $\mathrm{kg} ; A$ is leakage area, $\mathrm{m}^{3} ; Q_{a}$ is average leakage rate per unit area, $\mathrm{kg} / \mathrm{s} ; T$ is leakage duration, s.

Jet duration of different internal pressures and different leakage areas are shown in Fig. 7. 


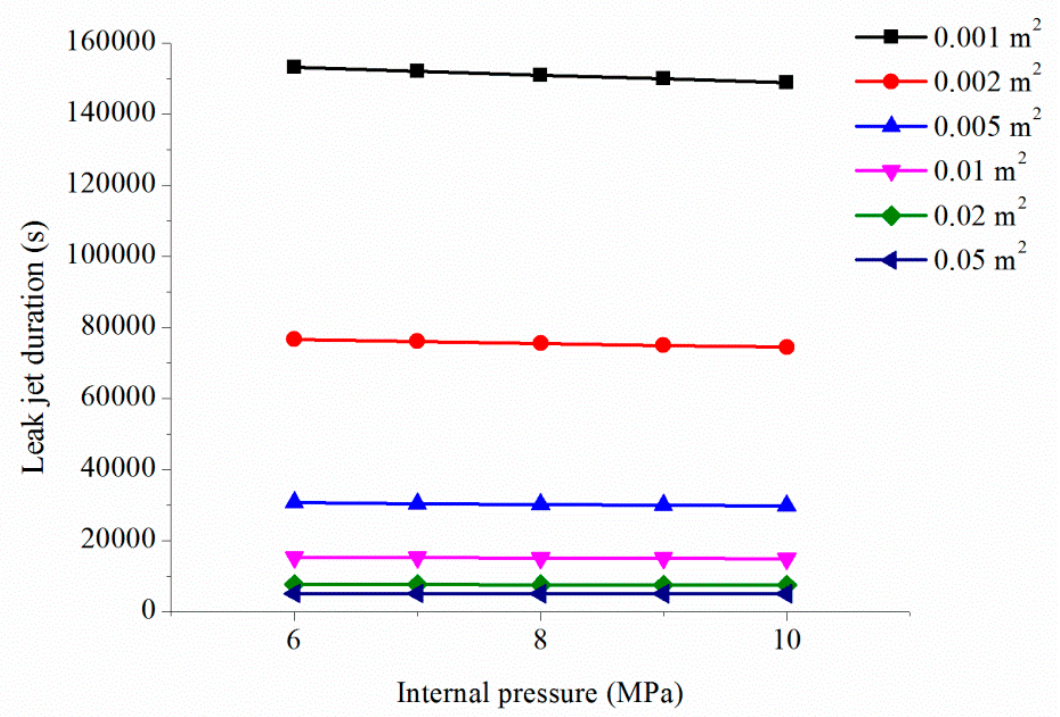

Fig.7 Jet duration of different internal pressures and different leak areas

It can be seen from Fig. 7 that the duration of the leakage jet is mainly affected by the leakage area and is less affected by the internal pressure in the pipeline.

\subsection{Optimization of block valve spacing}

It can also be seen from Fig. 7 that even if the valve chamber is closed in time, the total amount of gas leakage is also very large because of the long distance between the two end chambers and the delayed response of the monitoring system. If the distance between the two valve chambers is reduced, the duration of the leakage jet can be greatly reduced, and the difficulty of repairing tunnels is also reduced. Therefore, we consider setting the block valve at both ends of the tunnel. In the same circumstances, the leakage jet durations are shown in Table 4.

Table 4. Leakage jet duration after the block valve is set at both ends of the tunnel

\begin{tabular}{|c|c|c|c|c|c|c|}
\hline $\begin{array}{c}\text { Internal pressure } \\
(\mathrm{MPa})\end{array}$ & $0.001 \mathrm{~m}^{2}$ & $0.002 \mathrm{~m}^{2}$ & $0.005 \mathrm{~m}^{2}$ & $0.01 \mathrm{~m}^{2}$ & $0.02 \mathrm{~m}^{2}$ & $0.03 \mathrm{~m}^{2}$ \\
\hline 6 & $12242 \mathrm{~s}$ & $6121 \mathrm{~s}$ & $2448 \mathrm{~s}$ & $1224 \mathrm{~s}$ & $612 \mathrm{~s}$ & $408 \mathrm{~s}$ \\
\hline 7 & $12152 \mathrm{~s}$ & $6076 \mathrm{~s}$ & $2430 \mathrm{~s}$ & $1215 \mathrm{~s}$ & $608 \mathrm{~s}$ & $405 \mathrm{~s}$ \\
\hline 8 & $12063 \mathrm{~s}$ & $6032 \mathrm{~s}$ & $2413 \mathrm{~s}$ & $1206 \mathrm{~s}$ & $603 \mathrm{~s}$ & $599 \mathrm{~s}$ \\
\hline 9 & $11975 \mathrm{~s}$ & $5988 \mathrm{~s}$ & $2395 \mathrm{~s}$ & $1198 \mathrm{~s}$ & $594 \mathrm{~s}$ & $396 \mathrm{~s}$ \\
\hline 10 & $11888 \mathrm{~s}$ & $5944 \mathrm{~s}$ & $2378 \mathrm{~s}$ & $1189 \mathrm{~s}$ & 599 \\
\hline
\end{tabular}

It can be seen from Table 4 that the leakage jet duration is greatly reduced when the block valve distance is shortened.

\section{Ventilation scheme}

Before the rush-repairing, fans are usually used to discharge natural gas in the tunnel (so that the gas concentration is not at the limit of explosion). A single fan can be used, and multiple fans can also be used in parallel. Therefore, this paper optimizes the number of fan and the position of the fan.

\subsection{Numerical simulation}

As shown in Fig. 8, circle at different positions to present the location of fan. The geometry of the Yayingshan tunnel does not change, but the boundary conditions need to be changed. The boundary condition of fan is "Fan", 
moreover, in the actual ventilation process, both ends of the tunnel door need to be dug, so choose the "Pressure outlet" as the boundary condition of the tunnel.

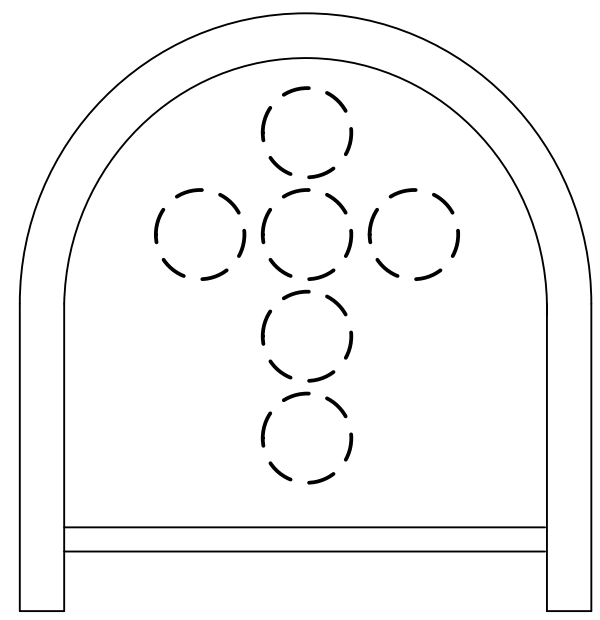

Fig. 8 Arrangement positions of fan

\subsection{Ventilation scheme for single fan}

(1) Air supply method

When there is a leak in the tunnel, there are two ways to empty the accumulated gas in the tunnel. One is to blow air into the tunnel, which is called press-in method. The second is to use the fan to form a negative pressure at the tunnel entrance, and to pump out the gas in the tunnel, which is called suction method. Due to the poor topographical conditions at the exit of the Yanyingshan tunnel, it is not possible to arrange the fan, as shown in Fig. 9, and therefore can only be arranged at the entrance.

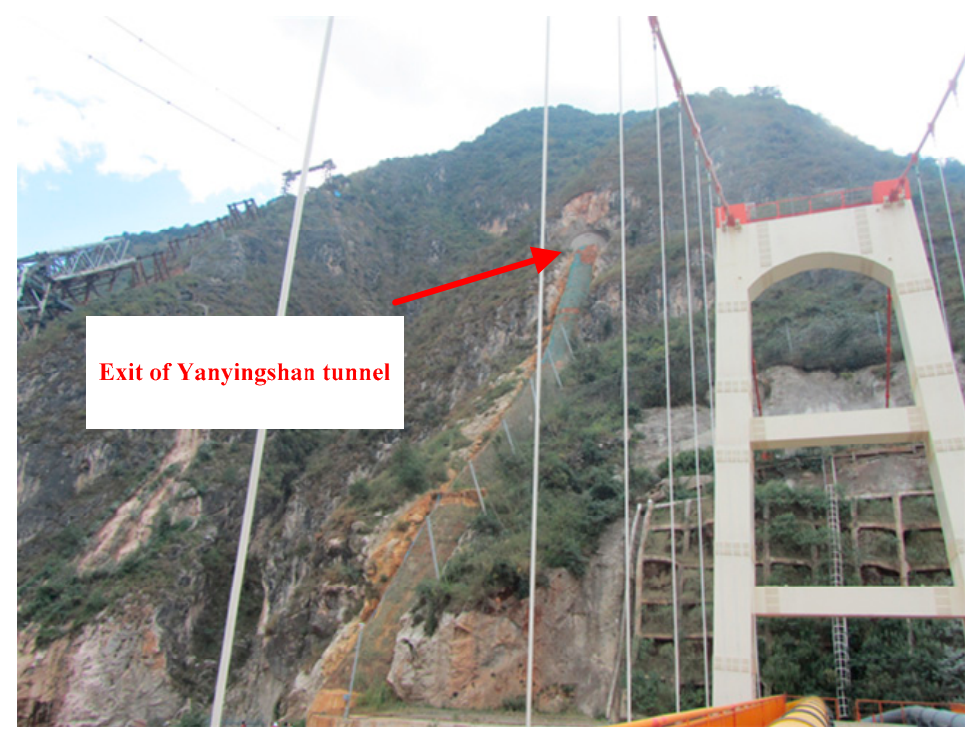

Fig. 9 Exit of Yanyingshan tunnel

Different types of fans vary greatly in their performance and geometric size. The air flow rate of the fan is usually in the range of 3-300 m33, total pressure range is $200-2400 \mathrm{~Pa}$, outlet wind speed range is $20-30 \mathrm{~m} / \mathrm{s}$ and the motor power is in the range of $2-55 \mathrm{~kW}$. In order to fully study the position of the fan, middle-sized fan with the diameter of $0.8 \mathrm{~m}$ is selected. The fan is located at the center of the tunnel, that is, $\mathrm{X}=1.9 \mathrm{~m}, \mathrm{Y}=1.9 \mathrm{~m}$. It is assumed that the tunnel is filled with gas and ventilated by the fan. In the meantime, the content of gas in the tunnel is measured. When the methane concentration in the calculated area is 0 , the gas in the tunnel can be considered to have been emptied. In general, the jet speed range is $15-30 \mathrm{~m} / \mathrm{s}$, in this speed range, the air flow generated by the fan can be considered as incompressible fluid flow, so air flow can be calculated through the fan jet velocity and diameter. The specific ventilation schemes of different air supply methods are shown in Table 5. The changes of gas concentration in the tunnel corresponding to the two methods of air delivery are shown in Fig. 10. 
Table 5. Ventilation schemes of different air supply methods

\begin{tabular}{|c|c|c|c|c|}
\hline Air supply method & Diameter of fan $(\mathrm{m})$ & $\begin{array}{c}\text { Horizontal position of fan } \\
\mathrm{X}(\mathrm{m})\end{array}$ & $\begin{array}{c}\text { Vertical position of fan Y } \\
(\mathrm{m})\end{array}$ & Air supply speed (m/s) \\
\hline Press-in & 0.8 & 1.9 & 1.9 & 30 \\
\hline Suction & 0.8 & 1.9 & 1.9 & 29.4 \\
\hline
\end{tabular}

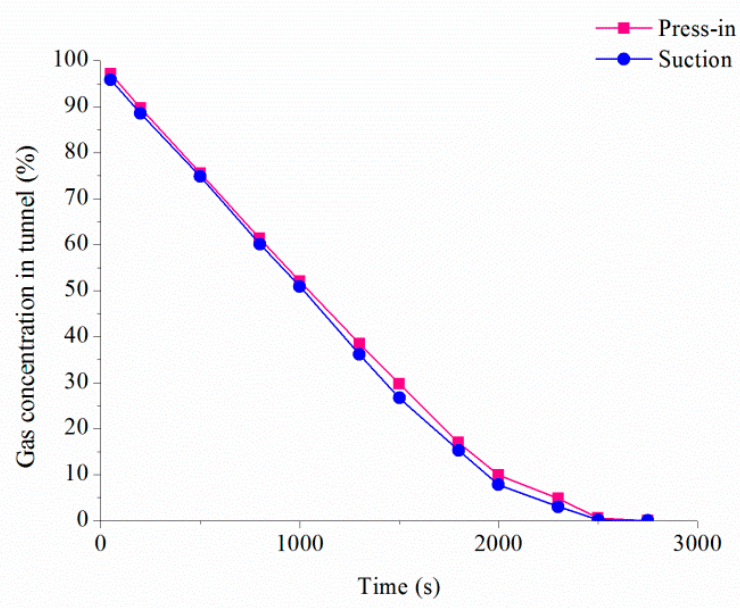

Fig. 10 Changes of gas concentration in the tunnel corresponding to the two methods of air delivery

It can be seen from Fig. 10 that the press-in method is more efficient, and when the press-in method is adopted, the gas near the inlet is discharged first and the fan can be moved to the depth of the tunnel and increase the discharge speed. The method of suction is not only less efficient, but also cannot move the fan position to the depth of the tunnel before the gas is emptied inside the tunnel. In summary, the press-in method is better.

(2) Height of fan

In order to find the best layout height of the fan, the fan is arranged at different height of the tunnel entrance, the diameter of fan is $0.8 \mathrm{~m}$, the distance between the fan and the left wall of the tunnel is $1.9 \mathrm{~m}$, the total pressure of the fan is $700 \mathrm{~Pa}$, and the outlet jet velocity is about $32 \mathrm{~m} / \mathrm{s}$. The efficiency of the different fan positions is shown in Table 6 .

Table 6. The efficiency of the different fan vertical positions

\begin{tabular}{|c|c|c|c|}
\hline Height of fan $(\mathrm{m})$ & $\begin{array}{c}\text { Average pressure of tunnel exit } \\
(\mathrm{Pa})\end{array}$ & $\begin{array}{c}\text { Average speed of tunnel exit } \\
(\mathrm{m} / \mathrm{s})\end{array}$ & Gas flow at tunnel exit $\left(\mathrm{m}^{3} / \mathrm{s}\right)$ \\
\hline 0.5 & 2.63 & 1.48 & 24.23 \\
\hline 1.5 & 2.85 & 1.53 & 24.88 \\
\hline 2.0 & 2.98 & 1.59 & 26.32 \\
\hline 2.5 & 3.13 & 1.66 & 26.92 \\
\hline 3.0 & 3.09 & 1.64 & 26.79 \\
\hline
\end{tabular}

It can be seen from Table 6 that the ventilation efficiency of the fan increases first and then decreases with the increase of the layout height because the jet of the fan is close to the bottom of the tunnel when the height of the fan is lower and the impact of the jet on the ground is greater (More energy loss). As the fan height increases, the impact of the jet on the tunnel wall becomes smaller, the energy loss decreases, and the ventilation efficiency increases. Ventilation efficiency is maximized when the fan layout height is about $2.5 \mathrm{~m}$. When the fan layout height is further increased, the energy loss of the jet increases again as it approaches the top of the tunnel, the fan ventilation efficiency decreases.

(3) Horizontal position of fan

After determining the optimal layout height, it is necessary to study the effect of the horizontal position on the ventilation effect. The height of the fan is $2.5 \mathrm{~m}$, the other conditions are unchanged. The ventilation efficiency of the fan at different horizontal positions is shown in Table 7. 
Table 7. The efficiency of the different fan horizontal positions

\begin{tabular}{|c|c|c|c|}
\hline Horizontal position of fan $(\mathrm{m})$ & $\begin{array}{c}\text { Average pressure of tunnel exit } \\
(\mathrm{Pa})\end{array}$ & $\begin{array}{c}\text { Average speed of tunnel exit } \\
(\mathrm{m} / \mathrm{s})\end{array}$ & Gas flow at tunnel exit $\left(\mathrm{m}^{3} / \mathrm{s}\right)$ \\
\hline 0.6 & 3.02 & 1.51 & 26.41 \\
\hline 1.0 & 3.08 & 1.58 & 26.87 \\
\hline 1.9 & 3.13 & 1.68 & 27.12 \\
\hline 2.8 & 3.09 & 1.57 & 26.88 \\
\hline 3.2 & 3.03 & 1.52 & 26.34 \\
\hline
\end{tabular}

It can be seen from Table 7 that the best horizontal position of fan is in the middle horizontal position of the tunnel because the fan jet will be affected by the wall when it is close to the wall on both sides and the energy loss is big. Near the middle position, the energy loss of air flow in the tunnel is the smallest and the reflux is the least.

\subsection{Ventilation scheme for multiple fans}

In order to improve the emptying efficiency of the gas in the tunnel, multiple fans can be used for ventilation, and the most common method is to use two fans in parallel. When the fans are used in parallel, if the distance between two fans is too small, fan jets will interfere with each other and become entwined and gradually merge, which will reduce fan ventilation efficiency. If the distance between two fans too big, although the interference between the jets decreases, the space inside the tunnel is limited, the fan will inevitably approach the wall of the tunnel, resulting in the loss of the jet energy. Therefore, how to arrange the distance between the two fans is an important issue. Two fans with diameter of 0.8 $\mathrm{m}$ are selected, the total pressure of the fan is $700 \mathrm{~Pa}$, the outlet jet velocity is about $32 \mathrm{~m} / \mathrm{s}$ and the height of fans are 2.5 $\mathrm{m}$. The ventilation effect corresponding to the different distances between two fans is shown in Table 8 .

Table 8. The ventilation effect corresponding to the different distances between two fans

\begin{tabular}{|c|c|c|c|}
\hline Distance between two fans $(\mathrm{m})$ & $\begin{array}{c}\text { Average pressure of tunnel exit } \\
(\mathrm{Pa})\end{array}$ & $\begin{array}{c}\text { Average speed of tunnel exit } \\
(\mathrm{m} / \mathrm{s})\end{array}$ & Gas flow at tunnel exit $\left(\mathrm{m}^{3} / \mathrm{s}\right)$ \\
\hline 0.1 & 6.25 & 2.21 & 36.93 \\
\hline 0.2 & 6.29 & 2.27 & 37.11 \\
\hline 0.5 & 6.34 & 2.29 & 37.25 \\
\hline 0.8 & 6.52 & 2.32 & 37.65 \\
\hline 1.0 & 6.33 & 2.28 & 37.18 \\
\hline 1.2 & 6.31 & 2.22 & 37.01 \\
\hline 1.4 & 6.28 & 2.19 & 36.93 \\
\hline 1.8 & 6.25 & 2.17 & 36.84 \\
\hline
\end{tabular}

It can be seen from Table 8 that the ventilation efficiency has little change with the increase of the distance between the two fans. This is because when the distance between the two fans is small, the jets of two fans will interfere with each other and cause great energy loss. When the distance between the two fans increases, although the energy loss caused by mutual interference of the fan jets becomes smaller, the energy loss caused by the tunnel wall on the jet (the distance between the jet and the wall decreases) increases, so the ventilation efficiency does not change much. Fig. 11 shows the airflow velocity vector at the tunnel entrance, it can be seen that when the distance between the two fans is 0.8 $\mathrm{m}$, reflux is the least. Therefore, considering Table 8 and Fig. 11, when the distance between two fans is $0.8 \mathrm{~m}$, the ventilation efficiency is the highest. 


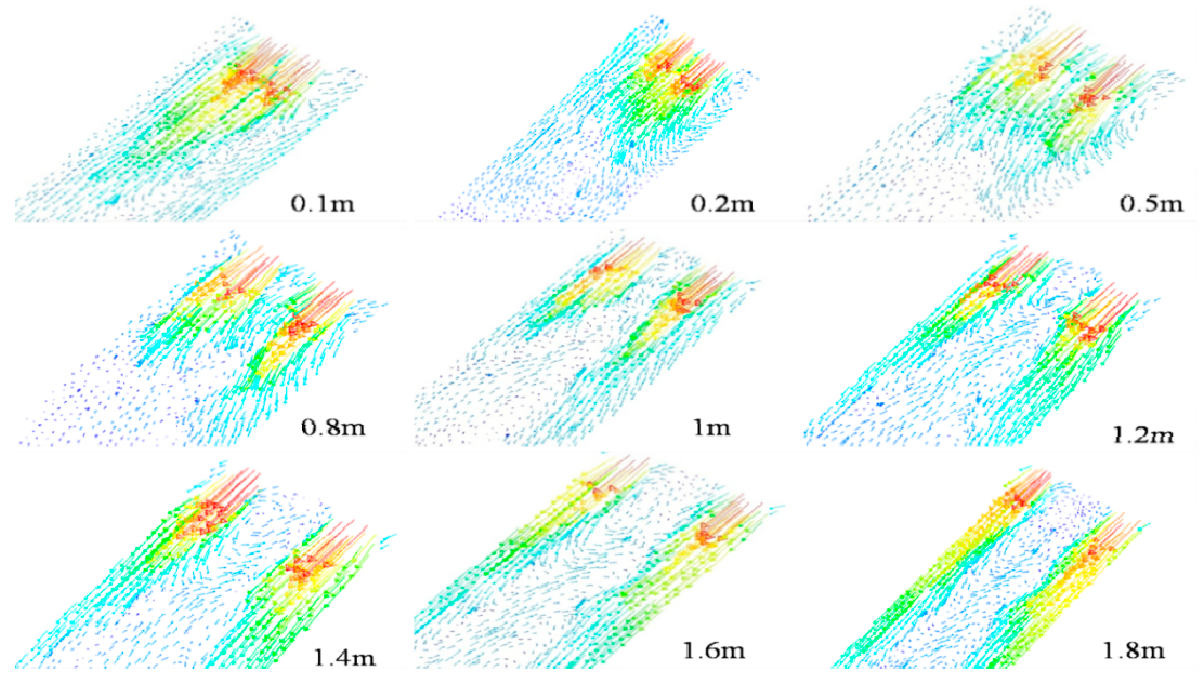

Fig. 11 Airflow velocity vector at the tunnel entrance

\section{Conclusions}

(1) The duration of the leakage jet is mainly affected by the leakage area and is less affected by the internal pressure in the pipeline.

(2) The duration of the leakage jet will be greatly reduced when the distance between the two valve chambers is reduced.

(3) For the ventilation scheme using a single fan, the layout of the fan cannot be too close to the wall of the tunnel, which will increase the energy loss of the jet.

(4) The ventilation effect of using two fans in parallel is better than the ventilation effect of a single fan, and the distance between two fans cannot be too close.

\section{References}

1. European Gas Pipeline Incident Data Group, "EGIG gas pipeline incident: 9th Report of the European Gas Pipeline Incident Data Group (period 1970-2013),” http://www.egig.eu/uploads/bestanden/ba6dfd62-4044-4a4d-933c-07bf56b82383. Accessed 17 December 2015

2. Zhang, Z. H., Huang, K., Zhang X. L., and Lyu, Y., and Liu, Y. Z., "Study on leakage laws and ventilation scheme of natural gas pipeline in Yanyingshan tunnel,” Journal of Safety Science and Technology, Vol. 12, No. 7, July 2016, pp. $42-48$.

3. Bring, A., Malmström, T. G., and Boman, C. A., "Simulation and measurement of road tunnel ventilation," Tunnelling and Underground Space Technology, Vol. 12, No. 3, July 1997, pp. 417-424.

4. Wei, J. F., Zeng, D. S., and Huang, Z. P., “Application of NS equation to tunnels' ventilation,” Chinese Quarterly of Mechanics, Vol. 22, No. 3, July 2001, pp. 383-388.

5. Peng F., "Analysis and calculation of ventilation of long highway tunnel," Highway Engineering, Vol. 33, No. 3, March 2001, pp. 88-90.

6. Vega, M. G., Díaz, K. M. A., and Oro, J. M. F., and Tajadura, R. B., and Morros, C. S., "Numerical 3D simulation of a longitudinal ventilation system: memorial tunnel case," Tunnelling and Underground Space Technology, Vol. 23, No. 5, September 2008, pp. 539-551.

7. Li, F., "High-gas tunnel ventilation management of the Yunding tunnel on Dacheng railway," Shanxi Architecture, Vol. 
35, No. 21, August 2009, pp. 347-349.

8. Hu, C. L., Zhang, H. L., and Wang, M., and Yu, Y. J., "Study on air flow distribution in tunnel under different axial distances among fans,"Sichuan Building Science, Vol. 40, No. 1, February 2014, pp. 94-97.

9. Huang, H., Chen, M., and Lu, W. B., and Yan, P., “Application of high-pressure and large-flow ventilator to tunneling ventilation," Water Resources and Hydropower Engineering, Vol. 45, No. 2, April 2014, pp. 97-99.

\section{Acknowledgement}

This article is funded by China Scholarship Council (201708030006). 